Repeated assertions by politicians that

the service is comprehensive and

available to everyone, when clearly it is

not, confuses patients.

\section{A call for honesty}

November 2001 saw the publication of the first General Dental Council Order, under Section 60 of the Healthcare Act 1999. This will, firstly, enable the General Dental Council to reduce its overall size from 50 to 29 members, but at the same time will triple the proportion of lay members; secondly the Order enables the Council to introduce, from 1st January 2002, compulsory continuing professional development for dentists as a condition of registration. Furthermore, this is only the first of such Orders; others are planned to include the strengthening of the procedures for dealing with misconduct and health, the introduction of procedures to deal with persistent poor performance, the introduction of a non-NHS complaints scheme and the registration of the entire dental team. All these reforms are with the stated intention of promoting high quality dentistry and ensuring that patients receive the protection which they deserve.

November 2001 also saw the publication of the wideranging National Health Service Reform and Health Care Professions Bill. This, firstly, implements the fundamental changes set out in the Department of Health document Shifting the Balance of Power within the NHS whereby power and resources will be devolved from existing Health Authorities to local Primary Care Trusts; secondly, the Commission for Health Improvement is strengthened by giving it special measures to deal with failing services, including powers to inspect dental practices; thirdly, establishing the Commission for Patient \& Public Involvement in Health to ensure that patients views are heard, to encourage participation on hospital and PCT boards, and requiring every Trust and PCT to establish a 'Patients Forum' which will monitor hospital performance in areas such as catering, cleaning and waiting times; fourthly, the Bill creates a 'Council for Regulation of Healthcare Professionals', a new and overarching body to oversee the activities of the GMC, the GDC and the other healthcare professional regulatory bodies.

At this time of great change and ever-increasing demands for quality dental care, our Association remains pledged to fulfill its stated objective of supporting its members in whatever sphere of practice they work. This new-look British Dental Journal should ensure that it remains both at the forefront of current dental publications and a valuable educational tool, whilst the recently launched BDA Good Practice Scheme provides patients with confirmation of their dentists commitment to a nationally agreed standard.

In order to meet the new challenges facing our profession, the BDA has not only responded in detail to the raft of recent consultation documents but has also produced the discussion paper Modern NHS Primary Care, Organisation and Development 2001 - 2005, recently sent to all members. Its purpose was to build on the discussions which have taken place with the Department of Health at a time when there is clearly an opportunity to influence the future. Current problems facing the NHS dental service have been identified and include those of workforce shortages, of the growing disillusionment - particularly amongst young dentists with NHS dentistry, quality issues, oral health inequalities, the damaging effects of patients charges, the outdated payment system, the lack of a preventive approach in GDS dentistry, and the advent of local Primary Care Trusts. More importantly, the document suggests new ways forward and offers potential solutions to the current problems facing the NHS dental service. Most importantly of all, this document calls for honesty. Honesty in NHS prioritisation, because repeated assertions by politicians that the service is comprehensive and available to everyone, when clearly it is not, confuses patients. It calls for Government to decide whether it wants a comprehensive service for all at a much higher cost than current spending, a limited service for everyone who wishes to use it, or a comprehensive service but limited to only those people the Government decides to provide for.

The Government's honest response is eagerly awaited by both us and by our patients.

Peter Swiss, BDA President 